\title{
Correlation of SARS-CoV-2 Subgenomic RNA with Antigen Detection in Nasal Midturbinate Swab Specimens
}

Katherine Immergluck, ${ }^{1}$ Mark D. Gonzalez, Jennifer K. Frediani, Joshua M. Levy, Janet Figueroa, Anna Wood, Beverly B. Rogers, Jared O'Neal, Roger Elias-Marcellin, Allie Suessmith, Julie Sullivan, Raymond F. Schinazi, Ahmed Babiker, Anne Piantadosi, Miriam B. Vos, Greg S. Martin, Wilbur A. Lam, Jesse J. Waggoner

Among symptomatic outpatients, subgenomic RNA of severe acute respiratory syndrome coronavirus 2 in nasal midturbinate swab specimens was concordant with antigen detection but remained detectable in $13(82.1 \%)$ of 16 nasopharyngeal swab specimens from antigennegative persons. Subgenomic RNA in midturbinate swab specimens might be useful for routine diagnostics to identify active virus replication.

\begin{abstract}
A ccurate detection of severe acute respiratory syndrome coronavirus 2 (SARS-CoV-2) infection is critical for patient management and infection control (1). Molecular diagnostics are highly sensitive in the acute phase of coronavirus diseases (COVID-19), but viral RNA remains detectable long after replicating virus can be isolated from respiratory samples (1-5). Antigen diagnostics, though often less sensitive, are touted as providing accurate detection during peak infectivity, thereby identifying persons most likely to transmit SARS-CoV-2 $(6,7)$.

Prolonged SARS-CoV-2 RNA detection has led to evaluation of molecular assays to detect subgenomic RNA (sgRNA) or negative-strand RNA, which are produced during active viral replication
\end{abstract}

Author affiliations: Emory University, Atlanta, Georgia, USA (K. Immergluck, M.D. Gonzalez, J.K. Frediani, J.M. Levy, J. Figueroa, A. Wood, B.B. Rogers, J. O'Neal, R. Elias-Marcellin, A. Suessmith, J. Sullivan, R.F. Schinazi, A. Babiker, A. Piantadosi, M.B. Vos, G.S. Martin, W.A. Lam, J.J. Waggoner); The Atlanta Center for Microsystems-Engineered Point-of-Care Technologies, Atlanta (K. Immergluck, M.D. Gonzalez, J.K. Frediani, J.M. Levy, J. Figueroa, A. Wood, B.B. Rogers, J. O'Neal, A. Suessmith, J. Sullivan, R.F. Schinazi, M.B. Vos, G.S. Martin, W.A. Lam, J.J. Waggoner); Children's Healthcare of Atlanta, Atlanta (M.D. Gonzalez, M.B. Vos)
$(2-5,8-10)$. sgRNA detection has predominantly been studied in hospitalized adults who have COVID-19 (2,3,5,8,9); published reports have not compared sgRNA and antigen detection, which should be highly correlated. We compared real-time reverse transcription PCR (rRT-PCR) detection of nucleocapsid sgRNA, the most abundant sgRNA in SARS-CoV-2-infected cells (2), with nucleocapsid antigen detection among symptomatic outpatients who had SARS-CoV-2 infections.

\section{The Study}

We obtained 88 nasal midturbinate and 39 nasopharyngeal swab specimens (PurFlock Ultra Flocked Swabs; Puritan Medical Products, https://www.puritanmedproducts.com) from 127 persons who came to COVID-19 testing centers affiliated with Emory University and Children's Healthcare of Atlanta (Atlanta, GA, USA) during January 2021. Inclusion criteria were a symptomatic respiratory illness for $\leq 7$ days and a positive, routine-care SARS-CoV-2 molecular test (nasopharyngeal swab specimen). The study was approved by the Emory University Institutional Review Board and Children's Healthcare of Atlanta.

We extracted total nucleic acids from $500 \mu \mathrm{L}$ of sample and eluted them into a volume of $50 \mu \mathrm{L}$ by using an EMAG Instrument (bioMérieux, https:// www.biomerieux.com). We tested eluates sideby-side in rRT-PCRs for sgRNA and total SARSCoV-2 RNA (genomic plus sgRNA). For sgRNA, we combined a forward primer in the leader sequence (5'-CGATCTCTTGTAGATCTGTTCTC-3') with the nucleocapsid 2 (N2) target reverse primer and probe (11).

${ }^{1}$ Current affiliation: Pomona College, Claremont, California, USA. 

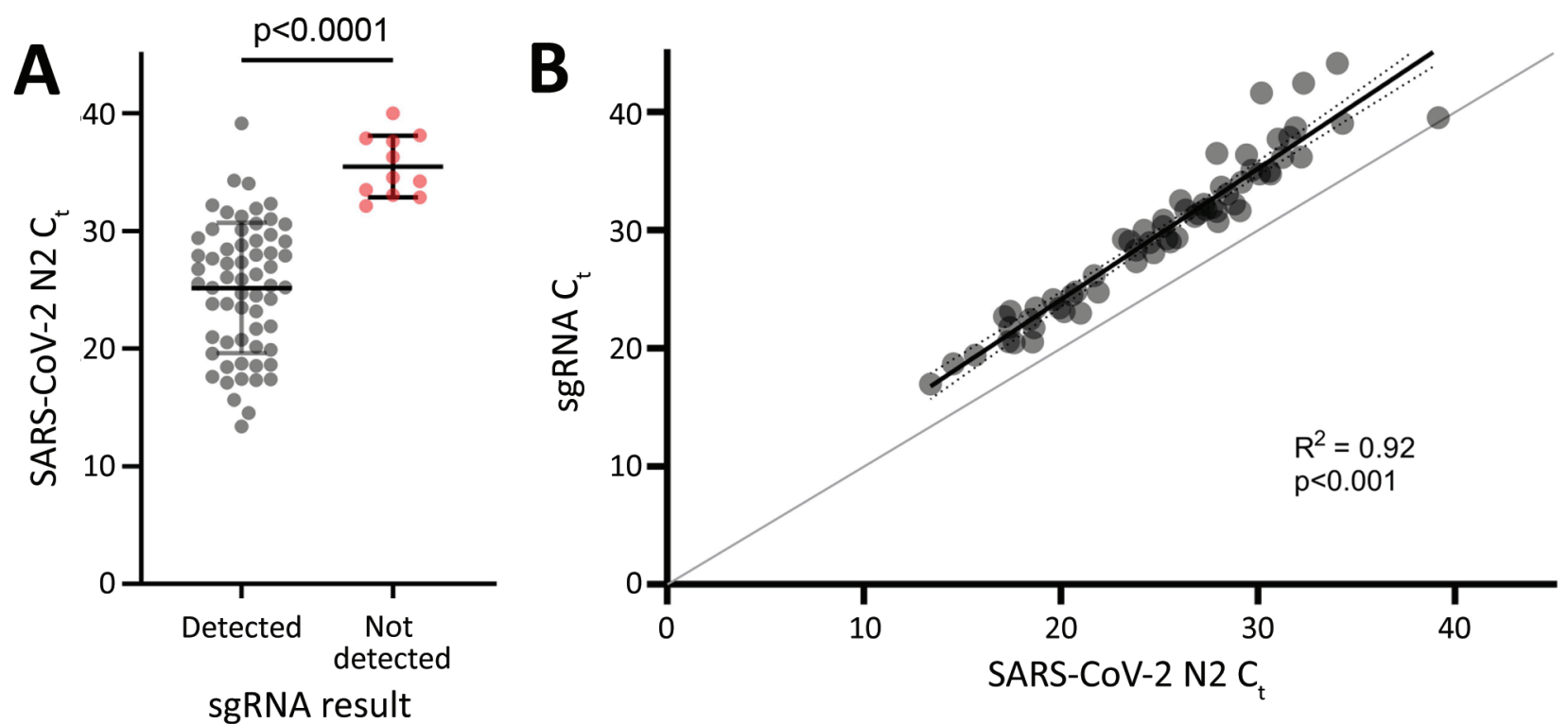

Figure 1. Correlation of sgRNA levels with total SARS-CoV-2 RNA in samples from study participants in Atlanta, Georgia, USA. A) N2 $C_{t}$ values for samples in which sgRNA was detectable (gray dots) or not detectable (red dots). Horizontal bars indicate means, and error bars indicate SDs. B) sgRNA $C_{t}$ values versus corresponding $C_{t}$ values for the $\mathrm{N} 2$ target. Results of simple linear regression (black line) and error bars (dotted lines) are shown. Line of identity (gray line) is shown for reference. C, cycle threshold; N2, nucleocapsid 2; SARS-CoV-2, severe acute respiratory syndrome coronavirus 2; sgRNA, subgenomic RNA.

We performed the sgRNA assay in $20-\mu \mathrm{L}$ reactions using the Luna Probe One-Step RT-qPCR Kit (New England Biolabs, https://www.neb.com) with $500 \mathrm{nmol} / \mathrm{L}$ of each primer, $250 \mathrm{nmol} / \mathrm{L}$ of probe, and $5 \mu \mathrm{L}$ of eluate by using the following conditions: $55^{\circ} \mathrm{C}$ for $15 \mathrm{~min}, 95^{\circ} \mathrm{C}$ for $2 \mathrm{~min}$, and 45 cycles of $95^{\circ} \mathrm{C}$ for $15 \mathrm{~s}$ and $60^{\circ} \mathrm{C}$ for $60 \mathrm{~s}$. We detected total SARS-CoV-2 RNA by using a duplex N2-RNase P rRT-PCR performed as described (12). We obtained an anterior nares swab specimen for nucleocapsid antigen detection with the Abbott BinaxNOW COVID-19 Ag Card (swabs supplied with the BinaxNOW kit; Abbott Laboratories, https://www.abbott.com) performed per the package insert.

The first 73 participants had a midturbinate swab specimen available for molecular testing (evaluation group) and have been described (13). The subsequent 54 participants had dedicated midturbinate $(\mathrm{n}=15)$ or residual nasopharyngeal $(\mathrm{n}=$ 39) swab specimens for molecular testing and available antigen test results (antigen testing group) (Appendix Figure 1, https://wwwnc.cdc.gov/EID/ article/27/11/21-1135-App1.pdf).

We estimated nucleocapsid sgRNA as a percentage of total RNA by calculating copies per microliter of sgRNA and total RNA for each sample based on a standard curve for each target and then calculating the percentage of sgRNA. We used unpaired t-tests to compare continuous variables and the Fisher exact test for testing categorical variables. We performed simple linear regression to compare cycle threshold $\left(C_{t}\right)$ values for sgRNA and total RNA. We conducted

Table 1. Demographic and clinical variables of study participants who had MT swab specimens in antigen-testing group analyzed for SARS-CoV-2 subgenomic RNA, Atlanta, Georgia, USA*

\begin{tabular}{|c|c|c|c|c|}
\hline Variable & Overall, $n=15$ & Antigen positive, $\mathrm{n}=8$ & Antigen negative, $\mathrm{n}=7$ & $\mathrm{p}$ value \\
\hline Mean age, y (SD) & $54.35(14.49)$ & $53.98(16.12)$ & $54.78(13.65)$ & 0.921 \\
\hline Female sex & $9(60.00)$ & $5(62.50)$ & $4(57.14)$ & 1.000 \\
\hline Mean days after symptom onset (SD)† & $4.14(2.44)$ & $3.88(2.23)$ & $4.50(2.88)$ & 0.655 \\
\hline MT swab specimen, rRT-PCR positive & $12(80.0)$ & $8(100.0)$ & $4(57.1)$ & 0.077 \\
\hline \multicolumn{5}{|l|}{ Race } \\
\hline White & $2(14.3)$ & 0 & $3(33.3)$ & 0.026 \\
\hline Black/African American & $11(78.6)$ & $8(100.0)$ & $3(50.0)$ & NA \\
\hline Asian & $11(78.6)$ & $8(100.0)$ & $3(50.0)$ & NA \\
\hline
\end{tabular}


Table 2. Correlation of SARS-CoV-2 subgenomic RNA with nucleocapsid detection in NP specimens from study participants analyzed for SARS-CoV-2 subgenomic RNA, Atlanta, Georgia, USA *

\begin{tabular}{|c|c|c|c|c|}
\hline Variable & Overall, $\mathrm{n}=39$ & Antigen positive, $\mathrm{n}=20$ & Antigen negative, $\mathrm{n}=19$ & $p$ value \\
\hline Mean age, y (SD) & $8.6(5.8)$ & $9.8(5.6)$ & $7.4(5.8)$ & 0.148 \\
\hline Female sex & $16(41.0)$ & $8(40.0)$ & $8(42.1)$ & 0.894 \\
\hline Mean days after symptom onset (SD)† & $3.7(2.2)$ & $3.0(1.4)$ & $4.5(2.7)$ & 0.227 \\
\hline Repeat NP swab specimen, rRT-PCR positive & $36(92.3)$ & $20(100.0)$ & $16(84.2)$ & 0.106 \\
\hline \multicolumn{5}{|l|}{ Race } \\
\hline White & $26(66.67)$ & $13(65.0)$ & $13(68.42)$ & 0.077 \\
\hline Black/African American & $6(15.38)$ & $3(15.0)$ & $3(15.79)$ & NA \\
\hline Asian & $4(10.26)$ & $4(20.0)$ & 0 & NA \\
\hline Biracial & $3(7.69)$ & 0 & $3(15.79)$ & NA \\
\hline Hispanic ethnicity & $19(48.72)$ & $6(30.0)$ & $13(68.42)$ & 0.016 \\
\hline
\end{tabular}

analyses by using GraphPad version 9.02 (https:// www.graphpad.com) and SAS version 9.4 (https:// support.sas.com).

The evaluation group included midturbinate swab specimens from 36 adults and 37 children. All samples $(73 / 73)$ were positive for SARS-CoV-2 by rRT-PCR. Samples with detectable sgRNA (62/73, $84.9 \%$ ) had significantly lower $C_{t}$ values, indicative of higher viral loads, than samples without detectable sgRNA (mean $C_{t} 25.1$, SD 5.5, vs. mean $C_{t} 35.5$, SD 2.6; $p<0.0001$ ) (Figure 1, panel A). sgRNA was detectable in all samples $(49 / 49)$ that had N2 $C_{t}$ values $<30$ compared with $13(54.2 \%)$ of 24 samples that had $C_{t}$ values $\geq 30(p<0.0001)$. Although sgRNA rRTPCR amplification efficiency was slightly lower than that for the N2 assay, there was a strong linear correlation between sgRNA and N2 $C_{t}$ values (Figure 1, panel $\mathrm{B}$ ), and the assay provided linear sgRNA detection across the range of $\mathrm{N} 2 \mathrm{C}_{t}$ values observed in this study (Appendix Figure 2). sgRNA $C_{t}$ values were a mean of 4.8 (SD 1.8) cycles higher than corresponding $\mathrm{N} 2 \mathrm{C}_{\mathrm{t}}$ values, and nucleocapsid gene sgRNA accounted for a mean of $1.4 \%$ (SD 1.1\%) of SARS-CoV-2 RNA. Samples from children had higher viral loads than samples from adults, although the relative amount of sgRNA did not differ (Appendix Figure 3).

We complied characteristics of participants in the antigen-testing group who had midturbinate $(n=15)$ swab specimens (Table 1) and nasopharyngeal (n = 39) swab specimens (Table 2). All midturbinate swab specimens from participants who had detectable antigen $(\mathrm{n}=8)$ were also positive for sgRNA, whereas $0 / 4$ samples from antigen-negative persons were positive (к 1.0). Samples that had detectable sgRNA had significantly lower $\mathrm{C}_{t}$ values (mean 25.8, SD 2.7) than samples that did not have detectable sgRNA (mean 36.3, SD 1.8; $\mathrm{p}=0.002$ ) (Figure 2).

All (20/20) nasopharyngeal swab specimens from antigen-positive participants were positive for sgRNA. N2 $C_{t}$ values were significantly lower among antigen-positive participants (mean 18.2, SD 5.0) than antigen-negative participants (mean 27.8, SD 4.5; $\mathrm{p}<0.0001$ ) (Figure 2). sgRNA was detectable in $13(81.2 \%)$ of 16 nasopharyngeal swab specimens from antigen-negative persons. Days after symptom onset (when the sample was collected) did not differ significantly between antigen-positive and sgRNApositive/antigen-negative participants (mean 3.4, SD 1.9 days, vs. mean 3.8, SD 2.4 days; $\mathrm{p}=0.6$ ).

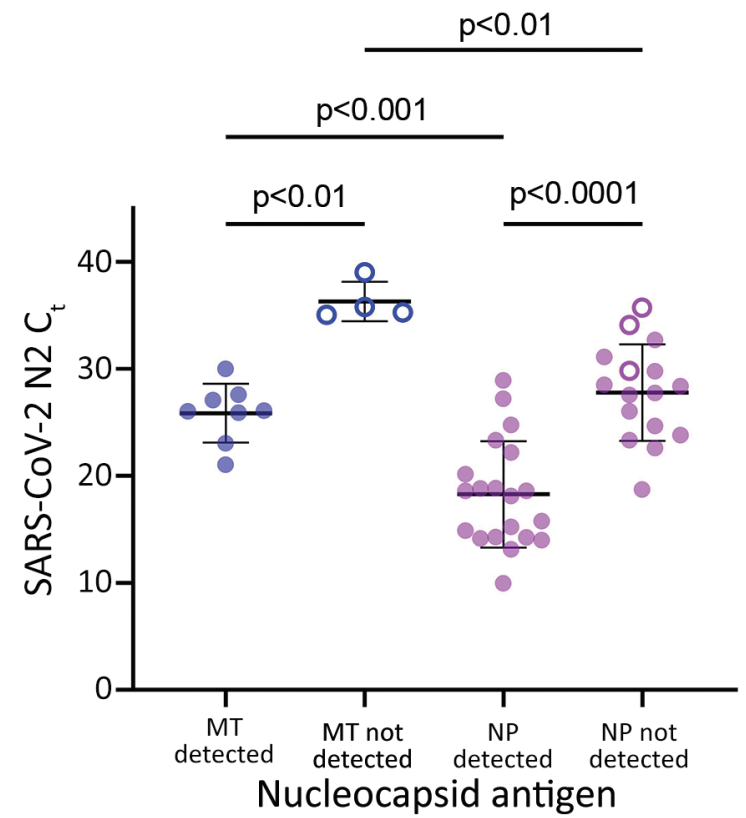

Figure 2. Concordance of SARS-CoV-2 sgRNA with nucleocapsid antigen detection in MT swab specimens, but not NP swab specimens, from study participants in Atlanta, Georgia, USA. sgRNA remains detectable in NP swab specimens for persons who showed negative results for nucleocapsid antigen. Symbols represent MT (blue) and NP (purple) swab specimens for persons with (filled circles) and without (open circles) detectable sgRNA. Horizontal bars indicate means, and error bars indicate SDs. $\mathrm{C}_{\mathrm{t}}$, cycle threshold; MT, nasal midturbinate; NP, nasopharyngeal; N2, nucleocapsid 2; SARS-CoV-2, severe acute respiratory syndrome coronavirus 2; sgRNA, subgenomic RNA. 
Nucleocapsid gene sgRNA accounted for a smaller percentage of total SARS-CoV-2 RNA in antigennegative participants (mean $0.6 \%$, SD $0.4 \%$ ) vs. antigen-positive participants (mean $1.0 \%$, SD 0.5\%; $\mathrm{p}=$ 0.012) (Appendix Figure 4). Compared with midturbinate swab specimens, nasopharyngeal swab specimens had lower $C_{t}$ values for RNase P (Appendix Figure 5).

\section{Conclusions}

SARS-CoV-2 sgRNA was detected in all samples from antigen-positive participants (28/28 total), consistent with identification of active viral replication and potential shedding $(4,5,8)$. However, among antigennegative participants, sgRNA detection varied between SARS-CoV-2 RNA-positive midturbinate $(0 / 4)$ and nasopharyngeal (13/16) swab specimens. Although nasopharyngeal swab specimens are expected to have higher viral loads (14), this difference did not appear to be the sole explanation. sgRNA represented a smaller proportion of total SARS-CoV-2 RNA in discordant nasopharyngeal swab specimens, and overall, nasopharyngeal swab specimens had higher amounts of human cellular material (lower RNase P $C_{t}$ values) than midturbinate swab specimens. Therefore, discordant sgRNA and antigen results in nasopharyngeal swab specimens probably resulted from persistent detection of waning SARS-CoV-2 infections with low levels of detectable sgRNA, which is only found in infected cells but insufficient viral replication to yield detectable nucleocapsid antigen in the anterior nares.

Nucleocapsid antigen was detected by using the widely available BinaxNOW COVID-19 Ag Card. This card demonstrates similar performance to other rapid antigen tests, which commonly detect nucleocapsid protein, and maintains analytical sensitivity against SARS-CoV-2 variants (7). Therefore, it provided a useful and relevant comparator for sgRNA detection.

Limitations of our study include a relatively small number of midturbinate swab specimens tested in the antigen-testing group, which was affected by the need for multiple swab specimens at a single time point. The race/ethnicity makeup of groups that had midturbinate and nasopharyngeal swab specimens differed (Tables 1, 2), although this limitation is not expected to have affected our findings (15).

In conclusion, sgRNA detection in midturbinate swab specimens correlates with nucleocapsid antigen and could be implemented as a molecular test to evaluate infectivity. Given the strong correlation between sgRNA, nucleocapsid antigen, and total SARS-CoV-2
RNA, these data also support use of antigen testing or establishment of rRT-PCR $C_{t}$ values as markers of active replication.

\section{Acknowledgments}

We thank the staff of the Atlanta Center for Microsystems Engineered Point-of-Care Technologies for their contributions and efforts, and study participants and family members for providing samples and clinical information.

This study was supported by the National Institutes of Health/National Institute of Biomedical Imaging and Bioengineering (grants U54 EB027690 $02 S 1$ and UL1 TR002378).

\section{About the Author}

At the time of this study, Ms. Immergluck was a research specialist in the Division of Infectious Diseases, Emory University School of Medicine, Atlanta, GA. She is currently completing her final year at Pomona College, Claremont, CA. Her research interest is development of new molecular methods for the detection of RNA viruses.

\section{References}

1. Centers for Disease Control and Prevention. Healthcare workers: information on COVID-19. 2021, March 31, 2021 [cited 2021] Apr 21 https:/ / www.cdc.gov/ coronavirus/2019-ncov/hcp

2. Dimcheff DE, Valesano AL, Rumfelt KE, Fitzsimmons WJ, Blair C, Mirabelli C, et al. SARS-CoV-2 total and subgenomic RNA viral load in hospitalized patients. J Infect Dis. 2021 Apr 19 [Epub ahead of print]. https:/ / doi.org/10.1093/ infdis/jiab215

3. Hogan CA, Huang C, Sahoo MK, Wang H, Jiang B, Sibai M, et al. Strand-specific reverse transcription PCR for detection of replicating SARS-CoV-2. Emerg Infect Dis. 2021;27:632-5. https:// doi.org/10.3201/eid2702.204168

4. Perera RA, Tso E, Tsang OT, Tsang DN, Fung K, Leung YW, et al. SARS-CoV-2 virus culture and subgenomic RNA for respiratory specimens from patients with mild coronavirus disease. Emerg Infect Dis. 2020;26:2701-4. https://doi.org/10.3201/eid2611.203219

5. van Kampen JJ, van de Vijver DA, Fraaij PL, Haagmans BL, Lamers MM, Okba N, et al. Duration and key determinants of infectious virus shedding in hospitalized patients with coronavirus disease-2019 (COVID-19). Nat Commun. 2021;12:267.https:// doi.org/10.1038/ s41467-020-20568-4

6. Mina MJ, Parker R, Larremore DB. Rethinking COVID-19 test sensitivity: a strategy for containment. N Engl J Med. 2020;383:e120.https://doi.org/10.1056/NEJMp2025631

7. Frediani JK, Levy JM, Rao A, Bassit L, Figueroa J, Vos MB, et al. Multidisciplinary assessment of the Abbott BinaxNOW SARS-CoV-2 point-of-care antigen test in the context of emerging viral variants and self-administration. Sci Rep. 2021;11:14604.https://doi.org/10.1038/ s41598-021-94055-1

8. Rodríguez-Grande C, Adán-Jiménez J, Catalán P, Alcalá L, Estévez A, Muñoz P, et al. Inference of active viral replication 
in cases with sustained positive reverse transcription-PCR results for SARS-CoV-2. J Clin Microbiol. 2021;59:e02277-20. https://doi.org/10.1128/JCM.02277-20

9. Wölfel R, Corman VM, Guggemos W, Seilmaier M, Zange S, Müller MA, et al. Virological assessment of hospitalized patients with COVID-2019. Nature. 2020; 581:465-9. https://doi.org/10.1038/s41586-020-2196-x

10. Dagotto G, Mercado NB, Martinez DR, Hou YJ, Nkolola JP, Carnahan RH, et al. Comparison of subgenomic and total RNA in SARS-CoV-2 challenged rhesus macaques. J Virol. 2021 Jan 20 [Epub ahead of print]. https://doi.org/10.1128/ JVI.02370-20

11. Centers for Disease Control and Prevention. Real-time RT-PCR panel for detection 2019-novel coronavirus, instructions for use, 2020 [cited 2021 Aug 17] https:/ / www.cdc.gov/ / coronavirus/2019-ncov/lab/ rt-pcr-panel-primer-probes.html

12. Waggoner JJ, Stittleburg V, Pond R, Saklawi Y, Sahoo MK, Babiker A, et al. Triplex real-time RT-PCR for severe acute respiratory syndrome coronavirus 2. Emerg Infect Dis. 2020;26:1633-5.https://doi.org/10.3201/eid2607.201285
13. Levy JM, Frediani JK, Tyburski EA, Wood A, Figueroa J, Kempker RR, et al. Impact of repeated nasal sampling on detection and quantification of SARS-CoV-2. Sci Rep. 2021;11:14903.https:/ / doi.org/10.1038/s41598-021-94547-0

14. Pinninti S, Trieu C, Pati SK, Latting M, Cooper J, Seleme MC, et al. Comparing nasopharyngeal and midturbinate nasal swab testing for the identification of severe acute respiratory syndrome coronavirus 2. Clin Infect Dis. 2021;72:1253-5. https://doi.org/10.1093/cid/ciaa882

15. Kociolek LK, Muller WJ, Yee R, Dien Bard J, Brown CA, Revell PA, et al. Comparison of upper respiratory viral load distributions in asymptomatic and symptomatic children diagnosed with SARS-CoV-2 infection in pediatric hospital testing programs. J Clin Microbiol. 2020;59:e0259320.https:/ / doi.org/10.1128/JCM.02593-20

Address for correspondence: Jesse J. Waggoner, Division of Infectious Diseases, Emory University School of Medicine, 1760 Haygood Dr NE, Rm E-169, Atlanta, GA 30322, USA; email: jjwaggo@emory.edu

\section{etymologia}

\section{Prototheca [pro"to-the'kə]}

\section{Rüdiger D. Ollhoff, Fábio P. Sellera, Fabio C. Pogliani}

$\mathrm{C}^{\mathrm{r}} \mathrm{r}$ rom the Greek proto- (first) + thēke (sheath), Prototheca is a genus of variably shaped spherical cells of achloric algae in the family Chlorellaceae. Wilhelm Krüger, a German expert in plant physiology and sugar production, reported Prototheca microorganisms in 1894, shortly

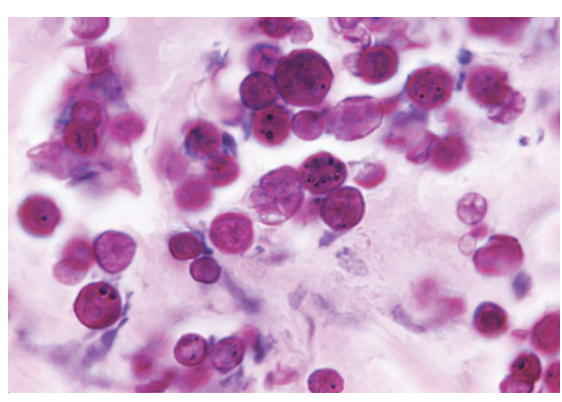

Figure 1. Periodic acid-Schiff-stained tissue sample from a case-patient who had protothecosis, showing several sphere-like cells of Prototheca spp. Source: Dr. Jerrold Kaplan, Centers for Disease Control, 1971.

\section{Sources}

1. Davies RR, Spencer H, Wakelin PO. A case of human protothecosis. Trans R Soc Trop Med Hyg. 1964;58:448-51. https:/ / doi.org/10.1016/0035-9203(64)90094-X

2. Dorland's illustrated medical dictionary. 32nd ed. Philadelphia: Elsevier Saunders; 2012.

3. Kano R. Emergence of fungal-like organisms: Prototheca. Mycopathologia. 2020;185:747-54. https://doi.org/10.1007/s11046-019-00365-4 after spending 7 years in Java studying sugarcane. He isolated Prototheca species from the sap of 3 tree species. Krüger named these organisms as $P$. moriformis and P. zopfii, the second name as a tribute to Friedrich Wilhelm Zopf, a renowned botanist, mycologist, and lichenologist.

Protothecosis affects humans Figure 2. Wilhelm and wild and domestic animals, pri- Krüger (1857-1947). marily marily causing mastitis in cows. Hu- Sugar Beet Research man protothecosis was reported in (http://www.ifz1964 from a skin lesion in a farmer goettingen.de). from Sierra Leone. There are increasing reports of infections in immunocompromised patients. Debates regarding Prototheca taxonomy persist.

4. Krüger W. Brief characteristics of some lower organisms in the sap flow of deciduous trees [in German]. Hedwigia. 1894;33:241-66.

5. Todd JR, Matsumoto T, Ueno R, Murugaiyan J, Britten A, King JW, et al. Medical phycology 2017. Med Mycol. 2018;56(suppl 1):S188-204. https:/ / doi.org/ $10.1093 / \mathrm{mmy} /$ myx162

Address for correspondence: Rüdiger D. Ollhoff, Programa de Pós-Graduação em Ciência Animal da Pontifícia Universidade Católica do Paraná, Rua Imaculada Conceição, 1155 Prado Velho, Curitiba 80215 901, Paraná, Brazil; email: daniel.ollhoff@pucpr.br

DOI: https://doi.org/10.3201/eid2801.211554

Author affiliations: Pontifícia Universidade Católica do Paraná, Curitiba, Brazil (R.D. Ollhoff); Universidade de São Paulo, São

Paulo, Brazil (F.P. Sellera, F.C. Pogliani); Universidade Metropolitana de Santos, Santos, Brazil (F.P. Sellera) 